\title{
sciendo
}

DOI: $10.2478 /$ rjti-2021-0007

ROMANIAN JOURNAL

OF TRANSPORT INFRASTRUCTURE

\section{STATIC AND DYNAMIC STRUCTURAL HEALTH MONITORING SYSTEM FOR BRIDGES}

\author{
Andrei Radoi, Eng., Monitron s.r.l., Bucharest, andrei@monitron.ro \\ Cezar Margineanu, Eng., Monitron s.r.l., Bucharest, cezar@monitron.ro \\ Constantin Ploesteanu, Eng., Monitron s.r.l., Bucharest, costel@monitron.ro \\ Vasile Pangratie, Eng., Monitron s.r.1., Bucharest, vasile@monitron.ro
}

\section{Rezumat}

Acest document descrie un sistem pentru monitorizarea statică și dinamică a sănătăţii structurale a podurilor, dar nu numai. Necesitatea dezvoltării sistemului a rezultat ca urmare a greutăţilor întâmpinate de autori la instalarea și operarea unor sisteme de monitorizare complexe, compuse din elemente de la diferiți producători, cu tehnologii de măsură, moduri de alimentare, moduri de comunicație si aplicații software diferite. Sistemul descris facilitează integrarea diferitelor tehnologii de măsură, de realizare și alimentare a senzorilor și de comunicație, într-un sistem unitar care permite atât măsurători statice cat și dinamice, simultan.

Cuvinte cheie: Poduri, Senzori, Monitorizarea Sănătății Structurale, Monitorizare statică și dinamică

\section{Abstract}

This document describes a system for static and dynamic monitoring of the structural health of bridges, but not only. The need to develop the system resulted from the difficulties encountered by the authors in installing and operating complex monitoring systems, composed of elements from different manufacturers, with different measurement technologies, power supplies, communication modes and software applications. The described system facilitates the integration of different measurements, sensors, power supplies and communication technologies, in a unitary system that allows both static and dynamic measurements, simultaneously.

Keywords: Bridges, Sensors, Structural Health Monitoring, Static and Dynamic Monitoring

\section{INTRODUCTION}

Bridges are critical elements of transport infrastructure requiring special activities to ensure its safety. One of these activities is monitoring their structural health - SHM. SHM refers to the assessment of the integrity of the components of 
ROMANIAN JOURNAL

OF TRANSPORT INFRASTRUCTURE

Andrei Radoi, Cezar Margineanu, Constantin Ploesteanu, Vasile Pangratie

Static and dynamic structural health monitoring system for bridges

a structure. Its condition can be altered over time, due to several factors: the phenomenon of aging materials, the action of environmental factors (temperature and humidity), accidental events. With the help of SHM systems, a forecast regarding the evolution of deterioration over time can be provided. Due to the intensification of road traffic, the wear of the road infrastructure becomes more accelerated, resulting in the obligation to implement SHM systems, in order to prevent accidents but not only.

The development of the new technologies for the manufacturing of the sensors, data acquisition systems and communications has led to the development of increasingly efficient monitoring systems, allowing both static monitoring and dynamic monitoring with the same equipment. Monitoring systems have also been developed that integrate several measurement technologies, allowing to obtain data sets that completely describe the health of the structures. In this document we will describe the implementation of a static and dynamic SHM system, as a result of a project within Competitiveness Operational Programme (COP) 2014-2020. The name of the project was Intelligent multiparameter System for complex and Integrated MONitoring of structures for disaster risk assessment and reduction - SIMON.

The need to develop such a system occurred as a result of the experience accumulated by the authors during the implementation of various monitoring systems for 6 new bridges on the A2 highway, for the new cable-stayed bridge in Agigea but also for other complex civil constructions. We have thus faced difficulties in implementing monitoring systems due to the need to create a unitary system using very different components, from different manufacturers, each with its own software application, its own sensor power supply, with or without a time synchronization system, with or without communication with the central unit. We aim to integrate the various measurement technologies, related to sensors, unifying the power supply of equipment and sensors, communication mode, synchronization mode and central software application. We have achieved this by creating a common communication, synchronization and power supply module adaptable to the different types of sensors used, based on PoE Ethernet technology. The monitoring system was designed so that static and dynamic measurements can be performed with the same equipment both during the initial tests and during the long-term monitoring of the structures. 
ROMANIAN JOURNAL

OF TRANSPORT INFRASTRUCTURE

Andrei Radoi, Cezar Margineanu, Constantin Ploesteanu, Vasile Pangratie

Static and dynamic structural health monitoring system for bridges

\section{MULTI-PARAMETRIC MONITORING OF THE BEHAVIOR OF BRIDGES}

Bridges are important structures that, by their destination, complete the transport networks, thus serving the mobility of goods and people. In general, this type of structure requires important investments, both in terms of design and execution costs and in terms of maintenance. The characteristics that describe the behavior of bridges over time are durability and longevity, characteristics that are difficult to estimate due to changes in environment and operating conditions in both frequency and size.

Structure health monitoring (SHM) is the process of evaluating the state of parameters and its variation, by acquiring and analyzing data, a process that takes place over time, continuously or periodically.

With the development of new technologies and especially with the increase in performance of electronic equipment, monitoring the health of bridges has become, in recent years, an increasingly common procedure. By collecting a lot of data related to the behavior in over time of the structure of bridges, it is possible to estimate and thus improve the ways of designing them, leading to better sized structures that can better cope with environmental or usage conditions.

The health monitoring systems of bridge structure, depending on the number and type of sensors, but also on their position, aim to:

- determine defects, stresses or displacements in the elements of the structure;

- determine the position and type of defects;

- determine the size of the defects.

A monitoring process performs a number of actions, such as:

- monitoring parameters with permanent devices;

- data acquisition, transfer and processing;

- interfacing the database with dynamic structure simulation algorithms;

- statistical comparison of recordings history;

- estimating and making decisions.

Depending on the type of monitoring, the concepts of punctual, periodic, permanent and online type are distinguished:

- a dedicated, punctual monitoring is performed in order to obtain a small amount of data, from a small number of sensors, to give information related to the general condition of the structure;

- periodic monitoring takes place at certain time intervals in order to determine the evolution over time of the bridge structure; 
ROMANIAN JOURNAL

OF TRANSPORT INFRASTRUCTURE

Andrei Radoi, Cezar Margineanu, Constantin Ploesteanu, Vasile Pangratie Static and dynamic structural health monitoring system for bridges

- permanent monitoring is necessary from the moment certain limits are exceeded, either related to the lifetime of the structure or the level of certain parameters or the evolution of the defects under monitoring or as a result of taken decisions;

- online monitoring applies to large, important structures that require the issuance of immediate alarm signals, in case of exceeding some limits.

\subsection{Types of bridges}

Bridges are structures that qualify as works of art, designed to overcome an obstacle. They consist of the superstructure, intended to take over the loads from the traffic, infrastructure, which takes the loads from the superstructure and transfers them to the land and the connection area with the embankment.

The superstructure is the part of the bridge that directly takes over the permanent and mobile loads that appeared during operation and transmits them to the infrastructure elements.

From the point of view of the composition of the bridges in longitudinal sense, the following categories of structural systems are distinguished:

a) Slab bridges:

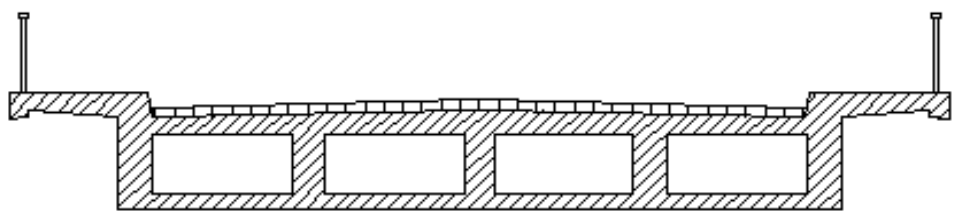

Figure 1. Slab bridge example

b) Beam bridges:

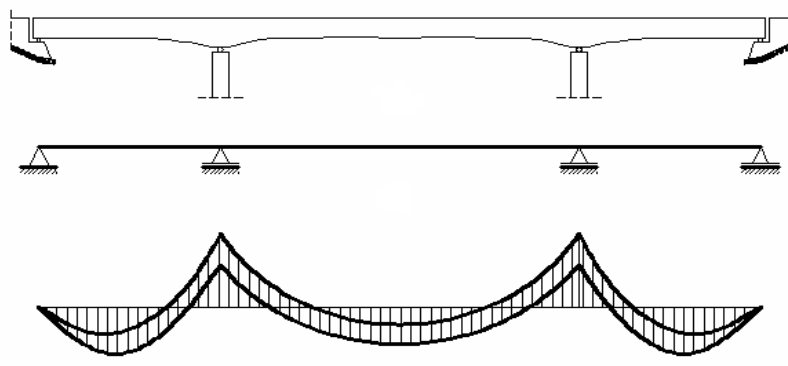

Figure 2. Beam bridge examples 
ROMANIAN JOURNAL

OF TRANSPORT INFRASTRUCTURE

c) Truss bridges:

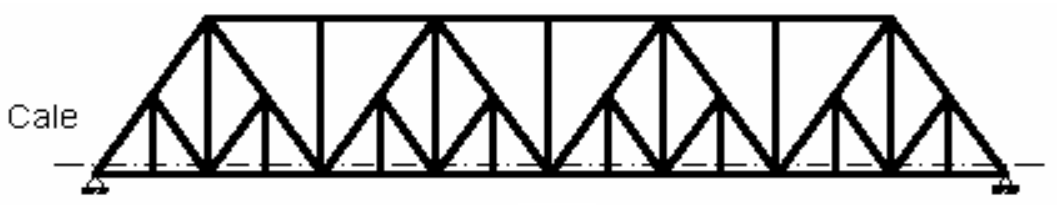

Figure 3. Truss bridge example

d) Arch bridges

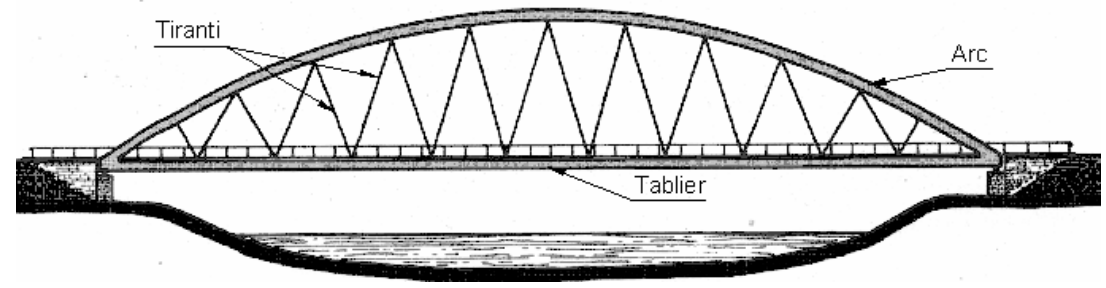

Figure 4. Arch bridge example

e) Cable stayed and suspension bridges

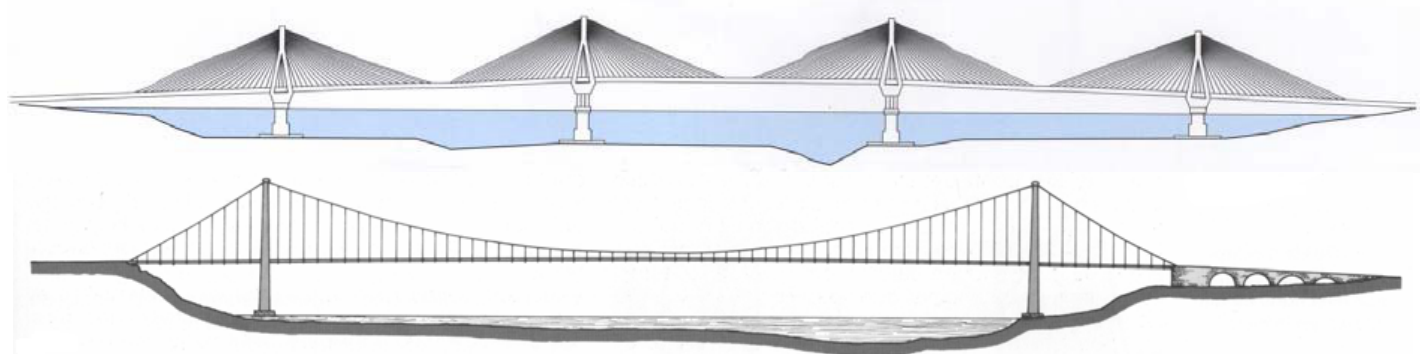

Figure 5. Cable stayed and suspension bridge example

\subsection{Monitoring parameters and limit values}

Finding the limit values for the load and the resistance of the bridge subjected to various critical influences, such as heavy traffic, storms, floods, earthquakes, is of particular importance due to the fact that even a single phenomenon can lead to the collapse of the structure. 
ROMANIAN JOURNAL

Continuous data acquisition is absolutely necessary due to the fact that such events are impossible or very difficult to predict, and monitoring at discrete moments of time can lead to missing the recording of critical loading moments.

The dynamic load factors are determined based on the predefined load classes and are calculated as the ratio between the maximum value of the strainer and its static value, using a low-pass filtering.

To determine the risk that is a result of material fatigue, the main parameter to be followed is the local effort measured with strain sensors. The effect of the loads is thus examined by the following actions:

- monitoring dynamic and static loads;

- determining the effects of dynamic loads;

- classification of the effects of loads;

- determining the maximum efforts and the frequency of their occurrence. These continuous monitoring activities aim to:

- evaluate the remaining lifetime of the structure;

- assess the structure's safety;

- determining the frequency of maintenance activities. In order to evaluate the structure's health, but also its response to loads, the human factor must be involved, through general observations and conclusions:

- strain measurements, bends, curves, inclinations, cracks, lead to conclusions related to the stability of foundations, global changes in rigidity, interruptions of continuity;

- observations related to resonant frequencies;

- selective monitoring of changes in vibration modes.

These activities are the result of monitoring the evolution over time of parameter values, such as:

- lengths and widths of known cracks;

- structural elements that present an increased risk of cracks;

- points of concentration of efforts;

- static displacements or vibration produced on the structural elements;

- stability of foundations;

- efforts in pre-tensioned elements.

Bridge monitoring activities are based on a very good knowledge of the structural characteristics and their response to loads, which is decisive in choosing the location of the sensors, their type and number and data analysis. This knowledge obtained through design calculations, analysis and simulations is an important premise for choosing how to configure monitoring systems, both functionally and economically, knowing that the level of design costs and implementation of these systems is an important one. 
ROMANIAN JOURNAL

OF TRANSPORT INFRASTRUCTURE

Andrei Radoi, Cezar Margineanu, Constantin Ploesteanu, Vasile Pangratie

Static and dynamic structural health monitoring system for bridges

\subsection{Types of sensors used for bridge monitoring}

An essential thing in the process of monitoring the structural health of bridges through sensor networks is that they have a robust construction, in order to operate stably for a long time, without being influenced by environmental changes such as temperature, humidity, electro-magnetic fields, etc.

The sensors can be divided into those that record local changes in the material and those that provide global information about the behavior of the structure or structural elements. Some of the sensors are embedded in the structure, others are applied on its surface.

Depending on the monitored parameters, the sensors used in the case of bridge monitoring can be:

Strain transducer. Choosing this type of transducers depends on the type of material on which they are applied, such as concrete or steel. Depending on the type of signal amplifier used, they work in the $100 \mathrm{kHz}$ frequency range and can measure resolutions of $0.1 \mu \mathrm{m} / \mathrm{m}$.

Bragg Grating Fiber. This type of sensor is suitable for measuring strain up to $10000 \mu \mathrm{m} / \mathrm{m}$, in a temperature range from -50 to $200^{\circ} \mathrm{C}$ and at frequencies of the order of MHz. The FBG sensors can be installed both embedded (in the structure and on its surface, and their length varies depending on the monitored element. They have a very good linearity, a low hysteresis and are insensitive to the influence of the environment.

Piezo film sensors. This type of sensor is used to measure the dynamic strain, having good characteristics on high frequencies. The level of these frequencies can be ensured by load amplifiers connected directly to the sensor.

Displacement sensors. LVDT sensors, which are based on the inductive principle of measuring the relative displacement between two points, are used for ranges from $\pm 1 \mathrm{~mm}$ to $\pm 50 \mathrm{~mm}$ and have extreme resolution in the temperature range from $-20^{\circ} \mathrm{C}$ to $120^{\circ} \mathrm{C}$. If this type of sensor cannot be applied due to mounting restrictions, or the measuring range, GPS-type sensors that record overall movements of very long bridge structures or stability and settling in foundations may be used.

Relative vibration measuring sensors. This type of sensor measures displacements and is used to determine the size of cracks or fissures. For this purpose, inductive, capacitive or conductive sensors are available. Depending on the measurement principle, movements between $0.1 \mu \mathrm{m}$ and $10000 \mu \mathrm{m}$ can be detected at frequencies up to $100 \mathrm{kHz}$. 
ROMANIAN JOURNAL

OF TRANSPORT INFRASTRUCTURE

Andrei Radoi, Cezar Margineanu, Constantin Ploesteanu, Vasile Pangratie

Static and dynamic structural health monitoring system for bridges

Vibrating wire. This type of sensor is based on the principle that the strain is proportional to the square root of the natural frequency in a vibrating wire. Vibrating wires are used to determine physical quantities, such as temperature, strain, pressure, and can be mounted on surfaces to be monitored or embedded in concrete for static or dynamic determinations.

Vibration speed sensors. To determine the absolute values of vibrations, these sensors are applied directly to the structure to be monitored and do not need reference points. They are used for measurements in the frequency range up to $1000 \mathrm{~Hz}$, but below $2 \mathrm{~Hz}$ problems can occur in measuring the amplitude or phase. Depending on the mechanical-electrical conversion element, these sensors can measure displacement (inductive or capacitive sensors) or speed (electro-dynamic sensors).

Inclinometers. These are sensors that use the capacitive measuring principle and operate up to a frequency of $5 \mathrm{~Hz}$, with a resolution between $0.1^{\circ}$ and $0.001^{\circ}$.

Fiber optic sensors. This type of sensor is suitable for detecting the occurrence of cracks in structures, as well as their size and location. Special attention is paid to large cracks, when due to relative movements, the sensor can be destroyed.

Temperature, humidity and corrosion sensors. Working in harsh environments, these sensors must be equipped with encapsulation protection systems. In choosing the right type of sensor for a particular application, the resolution, linearity, accuracy, range of measurements, their type (static or dynamic), environmental conditions, duration and pace of measurements must be taken into account.

\subsection{Measurement chain} elements:

The monitoring equipment used for bridges consists of the following

- Sensors;

- Signal conditioner (load, voltage, frequency, strain gauge);

- Data acquisition system with 16-24 bit analog-to-digital converter;

- Data analysis computer for data processing, data volume reduction and storage;

- Power source;

- Remote data transmission and management unit. 
ROMANIAN JOURNAL

OF TRANSPORT INFRASTRUCTURE

Andrei Radoi, Cezar Margineanu, Constantin Ploesteanu, Vasile Pangratie Static and dynamic structural health monitoring system for bridges

\section{SIMON MONITORING SYSTEM}

The aim of our project was the integration of the newest and most used technologies in the field, from which we chose the 5 following ones: MEMS accelerometers, vibrating-wire (VW) sensors, FBG fiber optic sensors, magnetoelastic (ME) sensors and electrical output (analog) sensors (LVDT, temperature, strain gauges, load cells). So, the monitoring system has the following architecture:
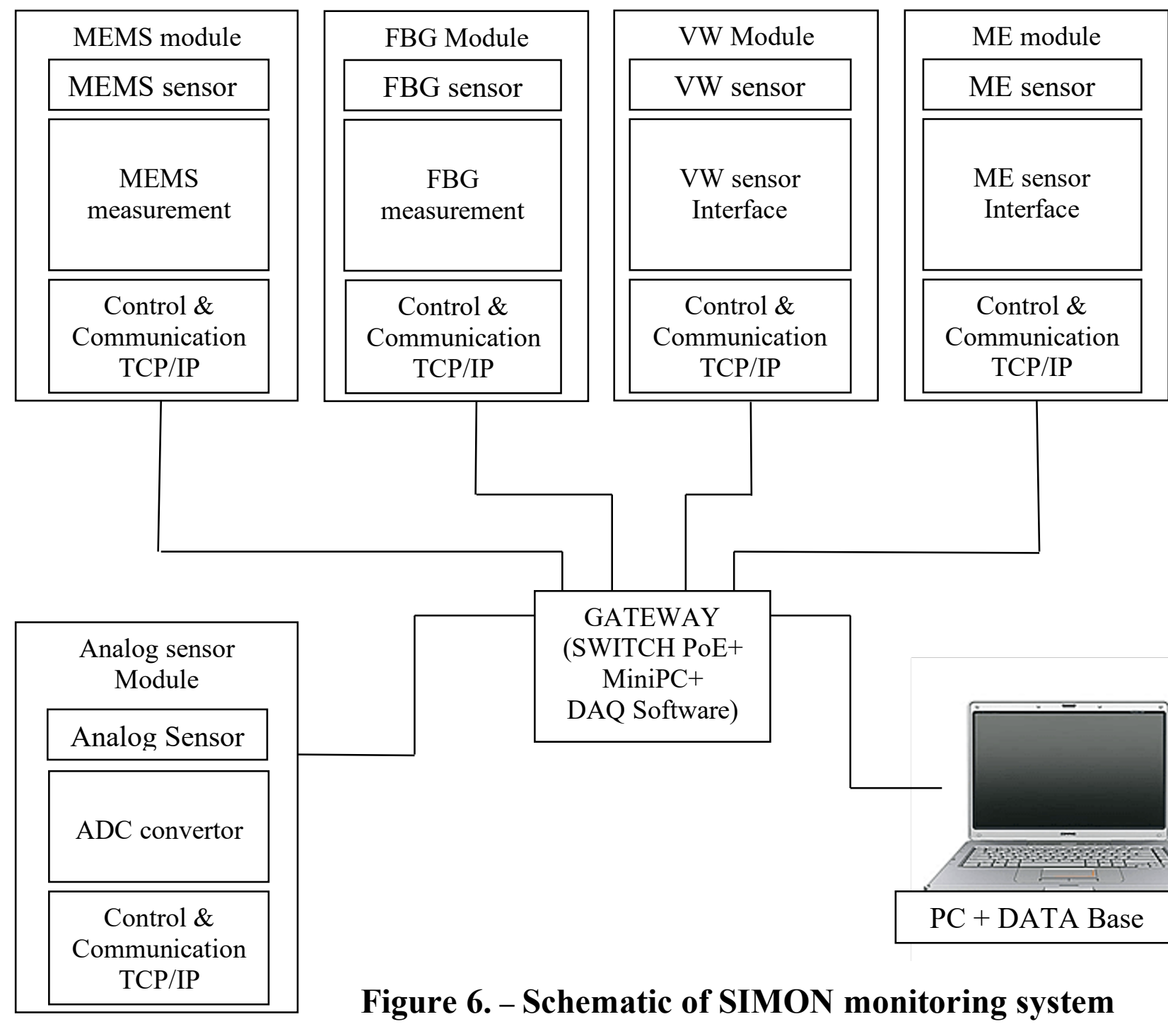

Figure 6. - Schematic of SIMON monitoring system 
ROMANIAN JOURNAL

OF TRANSPORT INFRASTRUCTURE

Andrei Radoi, Cezar Margineanu, Constantin Ploesteanu, Vasile Pangratie

Static and dynamic structural health monitoring system for bridges

The first two modules, MEMS accelerometers and FBG sensors, include also the measurement blocks, while the rest of the modules can integrate/interface the sensors from any third-party manufacturer.

\subsection{MEMS accelerometer module}

The MEMS accelerometer module included in the SIMON system consists in the following component blocks:

- Sensor block, MEMS technology (accelerometer, inclinometer and temperature);

- Sensor signal conditioning block;

- 24-bit analog-digital converter block with dedicated microcontroller;

- Communication block with microcontroller and Ethernet port (TCP/IP protocol);

- PoE power supply.

MEMS measurement modules can represent a complete solution for seismic instrumentation of buildings according to the Seismic design code P100$1 / 2013$.

The technical characteristics of MEMS accelerometer module are presented in the following table, for the two constructive versions:

Table 1. Accelerometer module characteristics

\begin{tabular}{|c|c|c|}
\hline Specifications/Version & MON-3AX1 & MON-AX2 \\
\hline Accelerometer & three axes, $\mathrm{X}, \mathrm{Y}$ and $\mathrm{Z}$ & three axes, $X, Y$ and $Z$ \\
\hline Noise & $25 \mu \mathrm{Grms} / \sqrt{\mathrm{Hz}}$ (average) & $0.2 \mu \mathrm{Grms} / \sqrt{\mathrm{Hz}}$ (average) \\
\hline Acceleration range & $\pm 2 \ldots \pm 8 \mathrm{G}$ & $\pm 12 \mathrm{G}$ \\
\hline Acceleration resolution & $3.9 \mu \mathrm{G} / \mathrm{LSB}$ & $0.06 \mu \mathrm{G} / \mathrm{LSB}$ \\
\hline Frequency band width & $400 \mathrm{~Hz}$ (selectable) & $100 \mathrm{~Hz}$ (selectable) \\
\hline Inclinometer & two axes, $\mathrm{X}$ and $\mathrm{Y}$ & two axes, $\mathrm{X}$ and $\mathrm{Y}$ \\
\hline Inclinometer range & $\pm 45^{\circ}$ & $\pm 45^{\circ}$ \\
\hline Inclinometer resolution & $0.25 \mu \mathrm{rad} / \mathrm{LSB}$ & $0.002 \mu \mathrm{rad} / \mathrm{LSB}$ \\
\hline Sampling frequency & up to $4000 \mathrm{~Hz}$ & up to $1000 \mathrm{~Hz}$ \\
\hline Operating temperature & $-40^{\circ} \mathrm{C} \ldots+50^{\circ} \mathrm{C}$ & $-40^{\circ} \mathrm{C} \ldots+50^{\circ} \mathrm{C}$ \\
\hline Protection degree & IP67 & IP67 \\
\hline Power supply & PoE & PoE \\
\hline Communication & Ethernet & Ethernet \\
\hline Connection & M12, 8 pins connector & M12, 8 pins connector \\
\hline Dimensions & $145 \times 100 \times 55 \mathrm{~mm}$ & $145 \times 100 \times 55 \mathrm{~mm}$ \\
\hline
\end{tabular}


ROMANIAN JOURNAL

OF TRANSPORT INFRASTRUCTURE

Andrei Radoi, Cezar Margineanu, Constantin Ploesteanu, Vasile Pangratie

Static and dynamic structural health monitoring system for bridges

\subsection{FBG fiber optic sensor module}

This technology benefits of the rapid development of the wide-spread communication technology. The FBG sensor module includes a wide spectrum laser interrogator, spectral dispersion element with VPG (Volume Phase Grating) and a detector area with InGaAs. This solution is fast, allowing parallel processing and continuous spectral detection. The FBG module can be manufactured in a scalable configuration, with 1,4 or 8 channels. Some of the main technical characteristics of the FBG module are presented in the following table, for the three constructive versions:

Table 2. FBG module characteristics

\begin{tabular}{|l|l|}
\hline Standard measurement range & $80 \mathrm{~nm}(1510-1590 \mathrm{~nm})$ \\
\hline Wavelength repeatability & $\pm 5 \mathrm{pm}$ \\
\hline Wavelength resolution & $1 \mathrm{pm}$ \\
\hline Minimum detectable variation & $\pm 1 \mathrm{pm}$ \\
\hline Number of optical channels & $1 / 4 / 8$ \\
\hline Maximum acquisition rate & $\begin{array}{l}\text { up to } 1 \mathrm{kHz}(\text { depending of number and } \\
\text { type of channels and sensors })\end{array}$ \\
\hline Number of sensors on each channel & 1 to 20 \\
\hline Power supply & PoE $/ 12 \mathrm{~V}$ \\
\hline Communication & Ethernet, IEEE 1588 \\
\hline Operating temperature & $0-40^{\circ} \mathrm{C}$ \\
\hline Relative humidity & $<90 \%$ at $40^{\circ} \mathrm{C}$ \\
\hline Connectors & $\mathrm{FC} / \mathrm{APC} ; \mathrm{E} 2000 / \mathrm{APC}$ \\
\hline
\end{tabular}

\subsection{Vibrating-wire sensors module}

Vibrating wire transducers (VW) represent a traditional, very popular solution, verified and therefore very widespread. Some of the main foreign companies that have developed products based on the principle of measuring with vibrating wire, are: ROCTEST - CANADA, GEOKON- USA, SISGEO - ITALY, RST INSTRUMENTS - USA, SLOPE INDICATOR - USA. The sensors based on the vibrating wire technology can be designed to measure a lot of physical parameters: strain, stress, pressure, tilt and displacement.

The vibrating wire module within the SIMON system can interface the vibrating wire sensors manufactured by the above-mentioned producers and not 
ROMANIAN JOURNAL

OF TRANSPORT INFRASTRUCTURE

Andrei Radoi, Cezar Margineanu, Constantin Ploesteanu, Vasile Pangratie

Static and dynamic structural health monitoring system for bridges

only. Some of the main technical characteristics of the Vibrating wire module are presented in the following table:

Table 3. Vibrating wire module characteristics

\begin{tabular}{|l|l|}
\hline Maximum number of channels & 8 \\
\hline Sensor coil excitation resistance & $50-5000 \mathrm{ohms}$ \\
\hline Measurement range & $400-6000 \mathrm{~Hz}$ \\
\hline Sensor coil excitation voltage & $0- \pm 3 \mathrm{~V}$ \\
\hline Resolution & $10 \mathrm{mHz}$ \\
\hline Sampling frequency & $1-200 \mathrm{~Hz}$, synchronous all channels \\
\hline Temperature measurement range & $-40^{\circ} \mathrm{C} \ldots+80^{\circ} \mathrm{C} ;$ \\
\hline $\begin{array}{l}\text { Temperature measurement } \\
\text { resolution }\end{array}$ & $0.1^{\circ} \mathrm{C}$ \\
\hline Temperature sensor & Thermistor, $3 \mathrm{kohm} \ldots . .10 \mathrm{kOhm}$ \\
\hline Communication port & $\mathrm{Ethernet}, \mathrm{IEEE} 1588$ \\
\hline Supply & $\mathrm{PoE}$ \\
\hline Operating temperature range & $-40^{\circ} \mathrm{C} \mathrm{...}+50^{\circ} \mathrm{C}$ \\
\hline Storage temperature range & $-40^{\circ} \mathrm{C} \mathrm{...}+70^{\circ} \mathrm{C}$ \\
\hline Protection grade & $\mathrm{IP} 20$ \\
\hline
\end{tabular}

\subsection{Magneto-elastic sensors module}

The magneto-elastic principle is used for the development of sensors for measuring the stresses in resistance elements with magnetic properties. In this case, there are fewer manufacturers, but due to the advantage of being able to be used in certain situations where other technologies cannot be used, this technology will probably also develop rapidly.

The main manufacturers of measuring systems with magneto-elastic transducers are: INSET - Czech Republic (Dynamag model) and INTELLIGENT INSTRUMENT SYSTEM - USA. This technology is used especially for complex infrastructures that involve the use of prestressed steel cables, e.g., cable-stayed or suspended bridges. The module was designed to interface with the sensors manufactured by INSET and the main technical characteristics are presented in the next table for the two constructive versions: 
ROMANIAN JOURNAL

OF TRANSPORT INFRASTRUCTURE

Andrei Radoi, Cezar Margineanu, Constantin Ploesteanu, Vasile Pangratie Static and dynamic structural health monitoring system for bridges

Table 4. Magneto-elastic sensors module characteristics

\begin{tabular}{|l|l|}
\hline Inner diameter of sensors & $5-240 \mathrm{~mm}$ \\
\hline Maximum number of sensors & $8 / 16$ \\
\hline Measurement range & $0-10 \mathrm{mWb}$ \\
\hline Resolution & $1 \mu \mathrm{Wb}$ \\
\hline Supply & $\mathrm{PoE}$ \\
\hline Communication & Ethernet, IEEE 1588 \\
\hline Operating temperature range & $-5^{\circ} \mathrm{C} \ldots 45^{\circ} \mathrm{C}$ \\
\hline Storage temperature range & $-40^{\circ} \mathrm{C} \ldots+70^{\circ} \mathrm{C}$ \\
\hline Protection degree & $\mathrm{IP} 20$ \\
\hline
\end{tabular}

\subsection{Electrical output (analog) sensors module}

This module has been included in the measurement system to allow the acquisition of data from classic sensors with unified output signal, sensors that are still used to monitor the health of structures. This module includes a signal conditioning block and a digital analog conversion block. The conditioned and digitized signal is transmitted directly to a central computer via the communication block with TCP/IP protocol or by mean of the GATEWAY module. The main technical characteristics of this module are presented in the following table:

Table 5. Electrical output sensors module characteristics

\begin{tabular}{|l|l|}
\hline Number of channels & 8 individually configurable channels \\
\hline Configurable sensors & -transducers with voltage output; \\
\hline & -transducers with current output; \\
\hline & -tensometric full bridge or half bridge; \\
\hline & -inductive transducers LVDT; \\
\hline & -potentiometric and resistive transducers; \\
\hline & -thermoresistances PT100, PT500, PT1000; \\
\hline & -thermistors \\
\hline Voltage input range & $\pm 10 \mathrm{~V} ;$ \\
\hline Current input range & Voltage resolution: $0.05 \mathrm{mV} ;$ \\
\hline Resistance type input range & $0-20 \mathrm{~mA}, 4-20 \mathrm{~mA}, 0-10 \mathrm{~mA} ;$ \\
\hline Thermoresistance types input & $0-1 \mathrm{k} \Omega, 0-5 \mathrm{k} \Omega, 0-10 \mathrm{k} \Omega ;$ \\
\hline & Types of RTD: PT100, PT500, PT1000; \\
\hline & Temperature resolution: $0.1^{\circ} \mathrm{C} ;$ \\
\hline
\end{tabular}


ROMANIAN JOURNAL

OF TRANSPORT INFRASTRUCTURE

Andrei Radoi, Cezar Margineanu, Constantin Ploesteanu, Vasile Pangratie Static and dynamic structural health monitoring system for bridges

\begin{tabular}{|l|l|}
\hline Tensometric bridge type input & $120 \Omega / 350 \Omega$ \\
\hline & Sensitivity: $1 \mathrm{mV} / \mathrm{V}, 2 \mathrm{mV} / \mathrm{V}, 5 \mathrm{mV} / \mathrm{V}$ \\
\hline LVDT bridge input & Excitation frequency: max. $5 \mathrm{kHz}$ \\
\hline & Excitation voltage: $\max .10 \mathrm{Vdc}$ \\
\hline Sampling frequency & Max. $8 \mathrm{kS} / \mathrm{s}$ \\
\hline Supply & PoE $/ 12 \mathrm{Vcc} / 24 \mathrm{Vca} / \mathrm{Max} .10 \mathrm{~W}$ \\
\hline Communication & Ethernet, IEEE 1588 \\
\hline Operating temperature range & $0^{\circ} \mathrm{C}-40^{\circ} \mathrm{C}$ \\
\hline Storage temperature range & $-40^{\circ} \mathrm{C} \ldots+70^{\circ} \mathrm{C}$ \\
\hline Protection degree & $\mathrm{IP} 20$ \\
\hline Dimensions L $\mathbf{~ I ~ x ~ H ~}$ & $295 \times 165 \times 115 \mathrm{~mm}$ \\
\hline
\end{tabular}

\subsection{GATEWAY Module}

The Gateway module for communication and data acquisition includes a PoE switch, a mini-PC and a resident software application. This module will provide communication, power supply and measurement synchronization, will perform primary data analysis and transmit relevant data packets to the remote main PC/Server which includes the database application that will integrate all measurements made by the monitoring system.

\subsection{DATA BASE application software}

The database application software facilitates the integration of all measurement technologies in a single measurement solution. The application that will generate the database, in addition to managing the data received from the measurement modules based on various technologies, will also fulfill the following functions:

- configuring the measurement processes for each of the measurement modules used;

- initiation or interruption of measurement sessions, according to a previous planning;

- synchronization of the measurements made by each of the measurement modules;

- presentation of measurement results in graphic and tabular form;

- possibility to preset warning and alarm levels for the values of the measured quantities; 
ROMANIAN JOURNAL

OF TRANSPORT INFRASTRUCTURE

Andrei Radoi, Cezar Margineanu, Constantin Ploesteanu, Vasile Pangratie

Static and dynamic structural health monitoring system for bridges

- marking with different colors the values of the measured quantities that exceed certain alarm thresholds, both in the graphic and in the tabular presentation;

- issuing warning messages when exceeding the preset levels for certain variables, via Internet or SMS;

- periodic transfer of data to another physical medium, to ensure data security.

\section{APPLICATION}

The monitoring system was already installed in some locations, the last ones are the Constanta Bridge in Bucharest (monitoring during the repairing activities with accelerometers and inclinometers) and the new Steaua Stadium in Bucharest (monitoring of the roof and the grand-stands with vibrating wire sensors, laser sensors, wind sensors and snow-load sensors). We present below some pictures with the sensors and the software application:

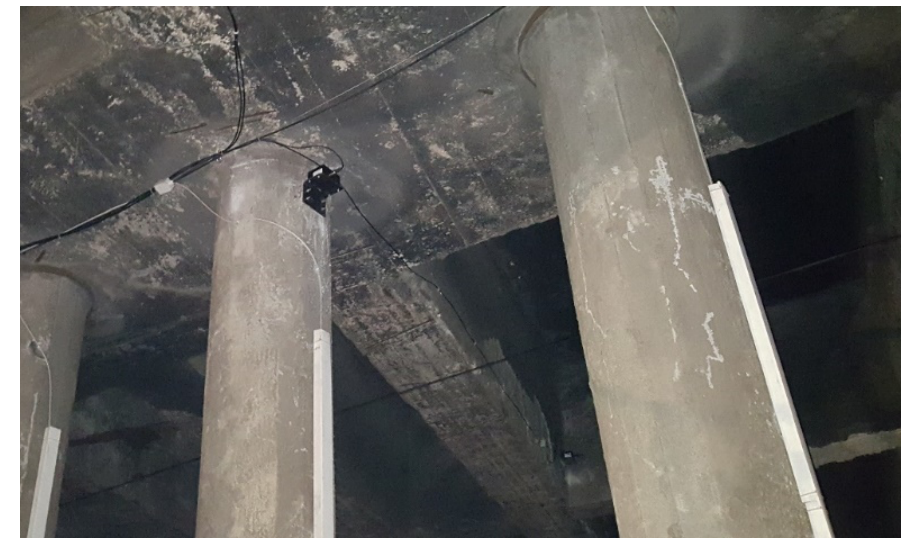

Figure 7. Accelerometer and FO sensors - Constanta Bridge

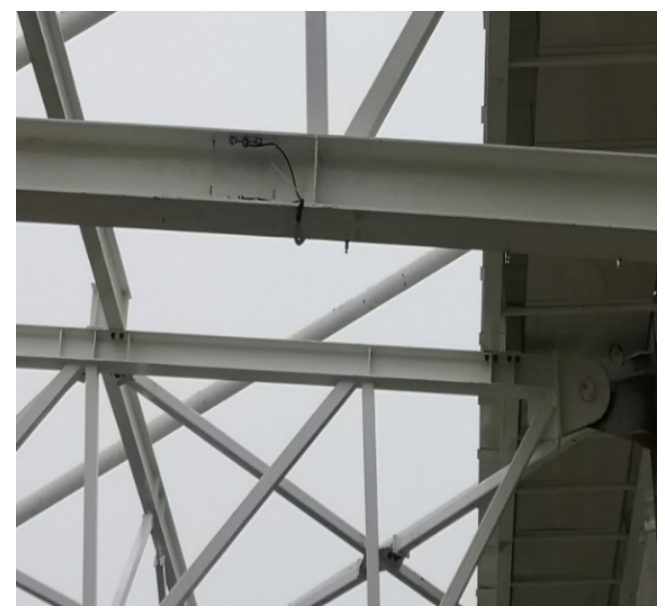

Figure 8. Vibrating wire sensors-Stadium

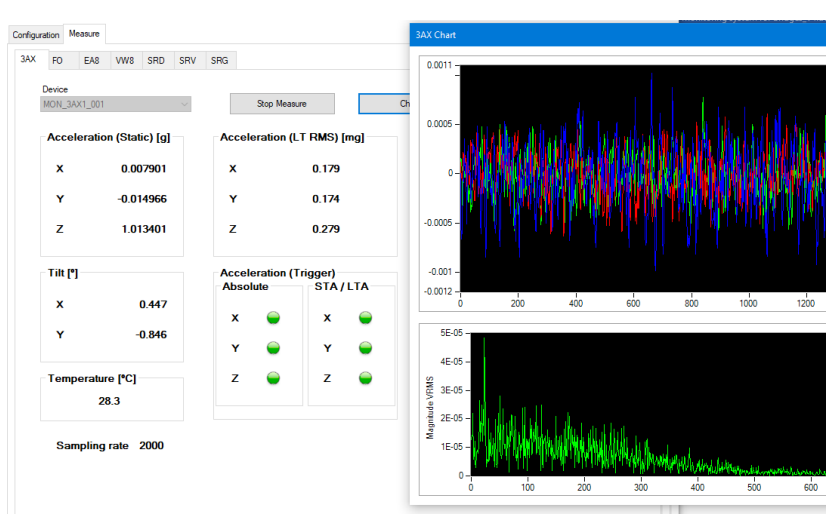

Figure 9. PC Application screen 


\section{CONCLUSIONS}

The results obtained in the recent applications in which SIMON monitoring system was installed showed us that it is suitable for the purpose for which it was designed, for applications both in road infrastructure and generally in the case of other complex structures. It also resulted in the need to redesign the measurement module for sensors with standard electrical output to facilitate its very complex configuration.

\section{REFERENCES}

[1] IR Răcănel, Căi de comunicații: Poduri, elemente generale, Editura Conspress Bucureşti, 2007

[2] Romanescu C., Non-destructive testing and Inspection System for health monitoring of road bridges, Presentation CESTRIN - Bridge Department, 11.07.2017.

[3] CL Ghindea, IR Racanel, R Cruciat, Dynamic testing of a reinforced concrete road bridge, Key Engineering Materials, 2014

[4] Jarosevic A: "Magnetoelastic method of stress measurements in steel" www.dynamag.com, Access: 2020

[5] B. Glisic and D. Inaudi, Fibre Optic Methods for Structural Health Monitoring, (C) 2007 John Wiley \& Sons, Ltd. ISBN: 978-0-470-06142-8

[6] www.monitron.ro, Blended technologies for SHM, Access 2021

[7] Inaudi D., Casanova N., Vurpillot S. 1997, Fiber Optic Deformation Sensors for Bridge Monitoring Proc. Int. Conf. on New Technologies in Structural Engineering, 2-5 July 1997, Lisbon

[8] Z. Alphose, "Structural health monitoring, damage detection and long-term performance," Engineering Structures, vol. 27, no. 12, pp. 1713-1714, 2005. 